\title{
Anca ilişkili vaskülitlerde tek merkez deneyimi
}

\section{Single center experience in anca-related vasculitides}

\author{
iD Muhammet Limon', iD Dilek Tezcan ${ }^{1}$, iD Semral Gülcemal ${ }^{1}$, iD Sema Yılmaz
}

${ }^{1}$ Selçuk Üniversitesi Tıp Fakültesi İç Hastalıkları-Romatoloji Anabilimdalı, Konya, Türkiye

$\ddot{\mathbf{O z}}$

Giriş-Amaç: Anti-nötrofil sitoplazmik antikor (ANCA) ilişkili küçük damar vaskülitleri granülomatöz polianjjiitis(GPA), eozinofilik granülomatöz polianjiiitis(EGPA) ve mikroskopik polianjiitistir(MPA). Bu çalışma ile kliniğimizde takip edilen ANCA ilişkili vaskülit sıklığı ve tedavi cevapları değerlendirilmiş̧ir.

Gereç-Yöntem: Bu çalışma retrospektif olarak Ocak 2015-Aralık 2018 arasında yapıldı. Çalışmaya 18 yaş üstü 2012 Chapel Hill sınıflamasına göre ANCA ilişkili vaskülit tanısı alan hastalar alındı.

Bulgular: Kliniğimizde 18 tane ANCA ilişkili vaskülit hastası retrospektif olarak değerlendirildi. Hastaların 12'si kadın, 6'sı erkekti. Hastaların yaş ortalaması 57.8 olarak bulundu. Hastaların 2 tanesi EGPA, 3 tanesi MPA, 13 tanesi GPA tanısı ile izlendiği görüldü. GPA tanısı ile izlenen hastaların 11 tanesi sistemik tutulumla, 2 tanesinin sınırlı tutulumla seyrettiği gözlendi. GPA tanısı ile izlenen hastalarda en sık tutulumun \%76 ile akciğer tutulumu, 2. sıklıkta \%53 oranında böbrek tutulumu olduğu tespit edildi. MPA ile izlenen hastaların 2 hastada böbrek tutulumu, 2 hastada akciğer tutulumu olduğu saptandı. EGPA tanısı ile izlenen hastaların 2 tanesinde akciğer tutulumu olduğu gözlendi. RF ve ANA pozitifliği GPA'da en yüksek tespit edildi. ANCA ilișkili vaskülitlerde indüksiyon tedavisinde pulse steroid ve siklofosfamid ile kombine olarak verildiği gözlendi. 3 GPA hastasının nüks olduğu ve nüks olan hastaların rituksimab ile izlendiği görüldü.

Tartışma-Sonuç: ANCA ilişkili vaskülitlerin klinik ve tedavisi benzerdir. ANCA ilişkili vaskülitlerin tedavisinde kısa sürede remisyon sağlanmalıdır. ANCA ilişkili vaskülitlerin takibinde nüks önemli bir problemdir. Nüks eden olgularda rituksimab tercih edilebilir.

Anahtar kelimeler: Vaskülit, sıklık, tedavi

\begin{abstract}
Introduction: Granulomatosis polyangitiis (GPA), eosinophilic granulomatosis with polyangiitis (EGPA and microscopic polyangiitis(MPA) are small vessel vasculitides associated with anti-neutrophil cytoplasmic antibody (ANCA). İn this study, the frequency of ANCA associated vasculitis and treatment responses in our clinic are evaluated.

Methods: This retrospective study was performed between January 2015- December 2018. 18 patients who older than 18 and diagnosed ANCA associated vasculitis according to the 2012 Chapel Hill Classification were included.

Results: İn totals, 18 patients who diagnosed ANCA associated vasculitis were included, 12 of whom females, 6 of whom males. The mean age of the patients was 57.8. Two of the patients were diagnosed with EGPA, 3 with MPA and 13 with GPA. 11 of the patients followed up with GPA with systemic involvement and 2 with limited involvement. The most common involvement in patients with GPA was pulmonary involvement with $76 \%$ and renal involvement in $53 \%$ of the patients. Pulmonary involvement was detected in 2 patients and lung involvement in 2 patients in MPA. Pulmonary involvement was observed in 2 patients with EGPA. RF and ANA positivity was highest in GPA. İt was observed in combination with pulse steroid and cyclophosphamide in the induction treatment of ANCA-associated vasculitis. It was seen that 3 GPA patients had recurrence and followed up with rituximab.
\end{abstract}

Discussion-conclusion: ANCA related vasculitides treatment and clinic are similar. İn the treatment of ANCA-associated vasculitis, remission should be achieved in a short time. In recurrent cases, rituximab may be preferred.

Keywords: Vasculitis, frequency, treatment

Yazışma Adresi: Muhammet Limon, Selçuk Üniversitesi Tıp Fakültesi İç Hastalıkları-Romatoloji Anabilimdalı 42130 Selcuklu/Konya

E-Posta:drmlimon@hotmail.com

Alınma Tarihi: 06.01.2020 / Kabul Tarihi: 14.09.2020 / Yayımlanma Tarihi: 15.06.2021 
Vaskülitler, kan damarlarının inflamatuvar destrüksiyonu ile karakterize heterojen bir grup hastalıktır. Primer vaskülitler 2012 Chapel Hill Toplantısına göre büyük, orta ve küçük damar vasküliti olarak ayrılır (1). Küçük damar vaskülitleri anti-nötrofil sitoplazmik antikor (ANCA) ilişkili vaskülitler -granülomatöz polianjiitis(GPA), eozinofilik granülomatöz polianjiitis(EGPA), mikroskopik polianjiitis(MPA); immünkompleks ilişkili vaskülitler (Antiglomerül bazal membran hastalığı, Henoch-Schonlein purpurası, hipokomplemantemik ürtikeryal vaskülit, kriyoglobülinemik vaskülit), organ spesifik vaskülit (kutanöz vaskülit, izole aortit, santral sinir sistemi vasküliti), değişken damar vasküliti (Behçet hastalığı, Cogan sendromu) olarak ayrılır. Tutulan damarların büyüklüğü, dağılımı ve şiddetine göre vaskülitler kendini sınırlayan hafif bir formdan multisistemik hastalık arasında değişen klinik sendromlarla sonuçlanabilir.

\section{Gereç-Yöntem}

Çalışmaya Ocak 2015-Aralık 2018 arasında 2012 Chapel Hill Toplantısına göre ANCA ilişkili vaskülit tanısı konulan 18 hasta alındı. Hastaların verileri retrospektif olarak tarandı. ANCA ilişkili vaskülit tanısı konulan hastaların tanı özellikleri ve tedavi cevabı retrospektif olarak araştırıldı.

\section{Bulgular}

Kliniğimizde 18 tane ANCA ilişkili vaskülit hastası retrospektif olarak değerlendirildi. Hastaların 12'si kadın, 6'sı erkekti. Hastaların yaş ortalaması 57.8 olarak bulundu (en küçük 41, en büyük 77). Hastaların 2 tanesi EGPA, 3 tanesi MPA, 13 tanesi GPA tanısı ile izlendiği görüldü. En sık görülen ANCA ilişkili vaskülit tanısı GPA olduğu saptand. GPA tanısı ile izlenen hastaların 11 tanesi sistemik tutulumla, 2 tanesinin sınırlı tutulumla seyrettiği gözlendi. GPA tanıs1 ile izlenen hastalarda en sik tutulumun \%76 ile akciğer tutulumu, 2. sıklıkta $\% 53$ oranında böbrek tutulumu olduğu tespit edildi. GPA tanısı ile izlenen 2 hastanın sinir sistemi tutulumları fasiyal paralizi ve santral sinir sistemi vasküliti olarak gözlendi. GPA tanısı ile izlenen 1 hastada orbital psödotümör tutulumu görüldü. MPA ile izlenen hastaların 2 hastada böbrek tutulumu, 2 hastada akciğer tutulumu olduğu saptandı. EGPA nedeniyle izlenen hastaların 2 tanesinde akciğer tutulumu olduğu gözlendi.

ANCA ilişkili vaskülit tanısı ile izlenen hastalardan 1 GPA hastasına eşlik eden romatolojik hastalık Sjögren sendromuydu.1 GPA hastasına eşlik eden malignite esansiyel trombositozdu. Hastaların organ tutulum özellikleri Tablo -I'de verilmiştir. GPA tanısı ile izlenen hastaların ortalama sedimantasyon değeri: $60 \mathrm{~mm} / \mathrm{saat}$ ve CRP: 70 $\mathrm{mg} / \mathrm{L}$ ile diğer ANCA ilişkili vaskülitlerden yüksek bulundu. RF pozitifliği GPA'da en yüksek bulundu. Antinükleer antikor pozitifliği GPA'da en yüksek tespit edildi. GPA'da kreatinin değeri ortalaması $1.46 \mathrm{mg} / \mathrm{dl}$, MPA'da $1.76 \mathrm{mg} / \mathrm{dl}$, EGPA'da $0.7 \mathrm{mg} / \mathrm{dl}$ bulundu. ANCA ilişkili vaskülit tanısı ile izlenen hastaların karaciğer fonksiyon testleri olağan olarak bulundu. MPA'da 24 saatlik idrarda protein: $1400 \mathrm{mg}$, GPA'da 1085 mg, EGPA'da 100 mg olarak bulundu. Hastaların organ tutulum özellikleri Tablo -II'de verilmiştir.

ANCA ilişkili vaskulitlerde indüksiyon tedavisinde pulse steroid ve siklofosfamid ile kombine olarak verildiği gözlendi. Siklofosfamid ile indüksiyon tedavisinin 6 ay ile sınırlı olduğu görüldü. ANCA ilişkili vaskülit tanılı hastalarımızda indüksiyon tedavisinde rituksimab verilmediği gözlendi. GPA tanısı ile izlenen hastalarda 1 tanesinin tedavi reddi ve 1 tanesinin eksitus olması nedeniyle tedavi almadı $\breve{g}_{1}$ görüldü. Sınırlı GPA tanısı ile izlenen hastalarda metotreksat ile tedavi verildiği gözlendi. 2 GPA'lı hastanın plazmafereze alındığı tespit edildi. ANCA ilişkili vaskülit nedeniyle izlenen 3 GPA hastasının nüks olduğu ve nüks olan hastaların rituksimab ile izlendiği görüldü.

Tedavi ilişkili morbidite olarak 2 hastada kortikosteroide bağlı avasküler nekroz, 2 hastada azatioprin altında kemik iliği süpresyonu görüldü. Üç y1llık retrospektif incelemede siklofosfamid alan hastalarda kemik iliği süpresyonu, infertilite, malignite, hemorajik sistit gözlenmedi. Üç yıllık takipte 2 hastada mortalite gözlendi. 1 GPA'l1 hasta serebrovaskuler olay nedeniyle, 1 MPA hastas pnömoniye bağl1 sepsis nedeniyle kaybedildi.

Tablo-I:ANCA ilişkili vaskülitlerde laboratuvar bulguları

\begin{tabular}{|l|l|l|l|}
\hline Laboratuvar & $\begin{array}{l}\text { Granülomatöz } \\
\text { polianjitis } \\
(\mathrm{n}: 13)\end{array}$ & $\begin{array}{l}\text { Mikroskobik } \\
\text { polianjiitis } \\
(\mathrm{n}: 3)\end{array}$ & $\begin{array}{l}\text { Eozinofilik } \\
\text { granülomatöz } \\
\text { polianjiitis }\end{array}$ \\
\hline Sedimantasyon & 60 & 28 & 40 \\
mm/saat & 70 & 38 & 10 \\
\hline CRP mg/l & 12700 & 9400 & 6100 \\
\hline WBC K/Ul & 10 & 9.8 & 12 \\
\hline Hemoglobin gr/dl & 444000 & 438000 & 285000 \\
\hline PLT K/Ul & 61 & 66 & 50 \\
\hline RF \% & 38 & 33 & 100 \\
\hline ANA \% & 100 & 0 & 50 \\
\hline C- ANCA \% & 0 & 100 & 50 \\
\hline P-ANCA \% & 1.46 & 1.76 & 0.7 \\
\hline Kreatinin mg/dl & 53 & 56 & 20 \\
\hline Üre mg/dl & 19 & 20 & 12 \\
\hline ALT U/L & 20 & 14 & 14 \\
\hline AST U/L & 1085 & 1400 & 100 \\
\hline Proteinüri mg/gün & & & \\
\hline
\end{tabular}

Tablo-II: ANCA ilişkili vaskülitlerin organ tutulumu

\begin{tabular}{|c|c|c|c|c|}
\hline \multicolumn{2}{|c|}{ Tutulum özellikleri } & $\begin{array}{l}\text { Granülomatöz } \\
\text { polianjiitis } \\
(n: 13)\end{array}$ & $\begin{array}{l}\text { Mikroskobik } \\
\text { polianjiitis } \\
(n: 3)\end{array}$ & $\begin{array}{l}\text { Eozinofilik } \\
\text { granüülomatöz } \\
\text { polianjiitis } \\
(\mathrm{n}: 2)\end{array}$ \\
\hline \multicolumn{2}{|l|}{ Kadın/Erkek } & $8 / 5$ & $2 / 1$ & $2 / 0$ \\
\hline \multicolumn{2}{|c|}{ Yaş ortalaması } & 57 & 63 & 61 \\
\hline \multirow[b]{2}{*}{ Komorbidite } & $\begin{array}{l}\text { Romatolojik } \\
\text { hastalık }\end{array}$ & 1 & 0 & 0 \\
\hline & Malignite & 1 & 0 & 0 \\
\hline \multicolumn{2}{|l|}{ Eklem } & 1 & 1 & 1 \\
\hline \multicolumn{2}{|l|}{ Akciğer } & 10 & 2 & 2 \\
\hline \multicolumn{2}{|l|}{ Böbrek } & 7 & 2 & 0 \\
\hline \multicolumn{2}{|c|}{ Akciğer ve böbrek } & 6 & 1 & 0 \\
\hline \multicolumn{2}{|l|}{ Cilt } & 1 & 0 & 0 \\
\hline \multicolumn{2}{|l|}{ Sinir sistemi } & 2 & 0 & 1 \\
\hline \multicolumn{2}{|c|}{ Kulak burun boğaz } & 2 & 0 & 0 \\
\hline \multicolumn{2}{|l|}{ Göz } & 1 & 0 & 0 \\
\hline \multicolumn{2}{|l|}{ Kalp } & 0 & 0 & 0 \\
\hline \multicolumn{2}{|c|}{ Hemodiyaliz gereksinimi } & 1 & 1 & 0 \\
\hline
\end{tabular}

Anca ilişkili vaskülitlerde deneyim - Limon ve ark. 
Tablo-III: ANCA ilişkili vaskülitlerde tedavi

\begin{tabular}{|l|l|l|l|l|}
\hline \multirow{4}{*}{ Tedavi } & $\begin{array}{l}\text { Granülomatöz } \\
\text { polianjiitis } \\
(\mathrm{n}: 13)\end{array}$ & $\begin{array}{l}\text { Mikroskobik } \\
\text { polianjiitis } \\
(\mathrm{n}: 3)\end{array}$ & $\begin{array}{l}\text { Eozinofilik } \\
\text { granülomä̈z } \\
\text { polianjiitis } \\
(\mathrm{n}: 2)\end{array}$ \\
\hline \multirow{4}{*}{ İndüksiyon } & Kortikosteroid & 9 & 3 & 2 \\
\cline { 2 - 6 } & Siklofosfamid & 9 & 3 & 2 \\
\cline { 2 - 6 } & Rituksimab & 0 & 0 & 0 \\
\cline { 2 - 6 } & Plazmaferez & 2 & 0 & 0 \\
\hline \multirow{4}{*}{ tedame } & Azatioprin & 6 & 2 & 2 \\
\cline { 2 - 6 } & Rituksimab & 3 & 0 & 0 \\
\cline { 2 - 6 } & $\begin{array}{l}\text { Mikofenalat } \\
\text { mofetil }\end{array}$ & 0 & 0 & 0 \\
\cline { 2 - 6 } & Metotreksat & 2 & 0 & 0 \\
\hline
\end{tabular}

Tablo-IV: ANCA ilişkili vaskülitlerde morbidite ve mortalite

\begin{tabular}{|l|l|l|l|l|}
\hline \multicolumn{2}{|l|}{ Morbidite/Mortalite } & $\begin{array}{l}\text { Granülomatöz } \\
\text { polianjiitis } \\
\text { (n:13) }\end{array}$ & $\begin{array}{l}\text { Mikroskobik } \\
\text { polianjitis } \\
\text { (n:3) }\end{array}$ & $\begin{array}{l}\text { Eozinofilik } \\
\text { granülomatöz } \\
\text { polianjitis } \\
\text { (n:2) }\end{array}$ \\
\hline \multirow{4}{*}{ Morbidite } & $\begin{array}{l}\text { Avasküler } \\
\text { nekroz }\end{array}$ & 2 & 0 & 0 \\
\cline { 2 - 5 } & Hemorajik sistit & 0 & 0 & 0 \\
\cline { 2 - 5 } & $\begin{array}{l}\text { Kemik iliği } \\
\text { süpresyonu }\end{array}$ & 1 & 0 & 1 \\
\cline { 2 - 5 } & Malignite & 0 & 0 & 0 \\
\hline Nüks & 3 & 0 & 0 \\
\hline Mortalite & 1 & 1 & 0 \\
\hline Ortalamatakip süresi/Ay & 20 & 10 & 48 \\
\hline
\end{tabular}

\section{Tartışma}

ANCA ilişkili vaskülitler, küçük çaplı damar vaskülitlerinin önemli bir bölümünü oluşturur. Küçük damar vaskülitlerinde, arteriyol, venül ve kapiller gibi küçük damarlar ön planda tutulur. ANCA ilişkili vaskülitlerin benzer klinik yönleri özellikle renal ve pulmoner tutulumla seyretmesidir.

GPA, sınırlı ve sistemik tutulumla seyredebilir. Sınırlı GPA üst solunum yolunda destrüktif lezyonlarla seyreder. GPA akciğerde nodül, kavite yapabilir. Akciğer tutulumu öksürük, nefes darlığı, hemoptizi gibi belirtilerle kendini gösterir. Nodüller, GPA'da en s1k görülen ve tipik kabul edilen radyolojik akciğer belirtisidir. Sıklıkla birden çok ve iki taraflı olup, sıklıkla da kaviteleşebilirler. Alveoler kapillerit, pulmoner hemorajiye neden olabilir. Diffüz interstisyel infiltrasyonlar ve hiler lenfadenopati GPA için olağan değildir ve tanı için biyopsi desteği gerekir. GPA'da hiler lenfadenopati olmayıp sarkoidozdan ayırımda önemlidir. Merkezimizde takip edilen GPA'lı olgularda pumoner nodül en s1k görülen akciğer bulgusu olup 6 hastada görülmüştür. Akciğerde kaviter lezyon 4, pulmoner hemoralji 4 olguda tespit edilmiştir. GPA'lı hastaların \%20'sinde başlangıçta glomerülonefrit görülür ve klinik seyri sırasında sıklığı \%80'e ulaşır. Proteinüri, glomerüler hematüri ve eritrosit silendirleri saptanır. GPA seyrinde hızlı ilerleyen glomerülonefrit gelişebilir. GPA seyrinde diffüz alveoler hemoraji ve hızlı seyirli glomerülonefrit birlikteliği ile seyreden polmono- renal sendrom \%33 sıklıkta görülür. Merkezimizde takip edilen GPA'lı olgularda pulmonorenal sendrom sıklığ1 \%46 olarak bulundu.

MPA arteriyol, kapiller ve venül tutulumunun baskın olduğu, immün birikimin çok az olduğu veya hiç olmadığı bir küçük damar vaskülitidir.

Anca ilişkili vaskülitlerde deneyim - Limon ve ark.
Erkeklerde kadınlara göre biraz daha sık görülür. MPA'nın temel klinik özellikleri; glomerulonefrit, pulmoner hemoraji, mononöritis multipleks ve ateştir. Hastalık akut ve ciddi bir başlangıç gösterebilir. Hastalık genel sistemik belirtilerle başlayabilir. Merkezimizde takip edilen MPA'li olgulardan 2 tanesi pulmoner hemoraji, 1 tanesi de glomerülonefrit ile tanı konulduğu tespit edilmiştir.

EGPA deri, periferik sinirler, akciğer, kalp ve gastrointestinal sistemi tutar. Hem periferik eozinofili, hem de dokularda eozinofilik infiltrasyon vardır. EGPA'nın genel özellikleri solunum yolunda eozinofilden zengin ve küçük orta damarlarda granülomatöz inflamasyondur. Merkezimizde takip edilen EGPA'l hastalarda böbrek tutulumu ve anlamlı proteinüri gözlenmedi. EGPA'l1 2 olgu da pulmoner hemoraji ile tanı konulmuştur.

ANCA indirekt immün floresan yöntemi ile boyanma özelliğine göre başlıca sitoplazmik (C-ANCA) ve perinükleer ANCA (P-ANCA) olmak üzere iki tiptir. GPA hastalarında C-ANCA testi \%60-90 pozitiftir (2). Negatif ANCA testi tanıyı dışlamaz. ANCA titresinde yükselme ve düşmeler çoğu zaman hastalık aktivitesini gösterebilir. Hiçbir zaman ANCA testi hastalık aktivite değerlendirmesinde tek rehber olmamalıdır. Sürekli yüksek pozitif seyreden veya negatif iken pozitifleşen veya titresi artan ANCA değerleri varlığında relaps riski nedeniyle dikkatli olmakta ve hastayı yakın izlemekte yarar vardır $(3,4)$. GPA'l1 18 olgunun tamaminda C-ANCA pozitif, MPA'l1 3 hastada P-ANCA +, EGPA'll 2 hastanın birinde C -ANCA diğerinde P-ANCA pozitif saptandi. Merkezimizde biyopsi ile ANCA ilişkili vaskülit tanısı konulan hasta olmadığı için antikor pozitifliği yüksek bulunduğu düşünüldü.

ANCA ilişkili vaskülitlerin tedavisinin temel amacı organ işlevlerinin korunmasıdır. Tedavi planlaması hastalık şiddetinin belirlenmesi, remisyon indüksiyonu, remisyon idamesi ve hastalığın uzun dönem takibini içermelidir. Tedavinin temelini kortikosteroid ve immünsüpresif ilaçlar ve bunların kombinasyonları oluşturur (5, 6). Sinırlı tutulum gösteren olgular haftada $25 \mathrm{mg}$ metotreksat ile kortikosteroid kombinasyonuna yanıt verebilir. Şiddetli hastalık vakalarında remisyonun sağlanması için rituksimab ya da siklofosfamid yüksek doz kortikosteroid ile birlikte verilir. Takip etmiş olduğumuz olgularda indüksiyon tedavisinde pulse kortikosteroid ile siklofosfamidin kombine olarak verildiği gözlendi. Siklofosfamid dozu olarak $500 \mathrm{mg}$ olarak 15 günde bir verildiği ve mesna ile birlikte verilmediği gözlendi. Siklofosfamid alan olgularda takip esnasında hemorajik sistit, kemik iliği süpresyonu, infertilite gözlenmedi. Siklofosfamid total 10 gr üzeri dozlarda hemorajik sistit riskini artırmaktadır (7). Siklofosfamid total dozu olarak 6 gr verildiği ve idame tedaviye geçildiği görüldü. Siklofosfamidi düşük dozda vermemiz nedeniyle kemik iliği süpresyonu, hemorajik sistit gibi yan etkiler gözlenmediği düşünüldü.

ANCAilişkili vaskülitlerin tedavisininde hayatı tehditeden durumlarda (intraalveolar hemoraji, hızlı ilerleyen glomerülonefrit) plazmaferez uygulanabilir. Plazmaferez tedavisinin etki mekanizması dolaşımdaki ANCA'ların, proinflamatuvar sitokinlerin, pıhtılaşma faktörlerinin ve çeşitli inflamasyon araçlarının hızla dolaşımdan uzaklaştırılmasıdır $(8,9)$. GPA ile izlenen 2 olgumuzda kreatinin değeri progresif olarak seyretmesi nedeniyle plazmafereze alındığı gözlendi. Plazmaferez uygulanan 2 hastanın tedavisine pulse kortikosteroid ve siklofosfamid eklenmesi ile kreatinin değerinin gerilediği ve diyaliz gereksinimi olmadan remisyona girdiği gözlendi. Hastalı̆̆ın kontrol edilmesi ve uzun süreli siklofosfamidin yan etkilerinden (infertilite, malignite, kemik iliği depresyonu, hemorajik sistit) kaçınmak için siklofosfamid ile 3-6 ay kısa süreli tedavi, remisyonun devamı için

Genel Tip Derg 2021;31(2)159-162 
azatioprin veya metotreksat ile uzun süreli tedavi önerilmektedir Hastalarda kortikosteroid tedavisi ile gelişebilecek yan etkiler konusunda dikkatli olunmalıdır. Kortikosteroid tedavisi altında 1 GPA'lı olguda femur başı avasküler nekroz gelişti. Bu hastalarda steroid dozu en kısa zamanda hedeflenen en düşük doza düşürülmeli, mümkünse kesilmelidir. Rituksimabla birlikte kortikosteroid tedavisi RAVE çalışmasında remisyon indüksiyon tedavisinde siklofosfamid ve kortikosteroid kombinasyonunu ile benzer etkinlikte olduğu tespit edilmiştir (10). Rituksimab nükseden GPA olgularında remisyon sağlanması için siklofosfamidden üstündür $(11,12)$. Rituksimab alan hastalarda malignite ve infertilite riski daha azdır. Plasebo kontrollü WGET çalışmasnda, GPA'da relapsları önlemede etanersept tedavisi etkisiz bulunmuştur. Hem infliksimab, hem de adalimumab renal vaskülit indüksiyon tedavilerinde ilave ilaç olarak kullanıldığında önemli bir yan etki görülmemiş ve steroid dozunun daha hızlı düşürülebilmiştir. Ancak henüz ANCA pozitif vaskülitlerde anti-TNF blokerlerinin kullanım yeri net değildir (13). Takip ettiğimiz ANCA ilişkili vaskülit hastalarında anti-TNF tedavi verilmemiştir.

ANCA ilişkili vaskülitlerde 1 ve 5 yıllık yaşam oranları, $\% 85$ ve \%75 olarak bildirilmiştir. Hastalığın başlangıcında yaygın ve şiddetli seyreden, geri dönüşümsüz hasarın hızla oturduğu ve vaskülitin ciddi relapslar yaptığ 1 hastalar, daha kötü prognoz gösterirler. 60 yaşdan genç hastalarda 1 yllılk mortalite $\% 5$ iken, 60 yaş üstünde bu oran $\% 23$ ve 70 yaş üstünde $\% 44$ olarak hesaplanmıştır (14). ANCA ilişkili vaskülitlerde, hastaların yaklaşık yarısında ilk 5 yıl içinde relaps görülürken, hastalık süresi uzadıkça relaps sıklığında azalma beklenir. Merkezimizde takip edilen 3 GPA hastas1 siklofosfamid ile indüksiyon, azatioprin ile idame tedavisi altında nüks olmuştur. GPA nedeniyle izlenen 3 hastada nüks medikal tedavinin 1.y1lından sonra görülmüştür. Nüks olan 3 GPA olgusunda rituksimab ile klinik remisyon gözlenmiştir. Merkezimizde takip edilen GPA'lı hastaların 6 tanesi idame tedavi olarak azatioprin, 2 tanesi metotreksat, 3 tanesi rituksimab almakta olup remisyondadır. 2 ECPA ve 2 MPA hastası idame tedavi olarak azatioprin almakta olup remisyondadır. Merkezimizde takip edilen ANCA ilişkili vaskülit tanılı 2 hastada medikal tedavinin ilk 6 ayında mortalite gözlenmiştir. GPA hastası serebrovasküler olay nedeniyle, MPA hastası pnömoniye bağlı sepsis nedeniyle kaybedilmiştir.

\section{Sonuç}

ANCA ilişkili vaskülitlerin klinik ve tedavisi benzerdir. Hastalık tanısinda zorluklar ve tedavilerin yan etkileri hala sorun olmaya devam etmektedir. ANCA ilişkili vaskülitlerin tedavisinde kısa sürede remisyon sağlanmalıdır ve daha az yan etki potansiyeline sahip immünsüpresif tedaviye geçilmelidir. Uzun süreli siklofosfamid alan hastalarda yan etki konusunda dikkatli olunmalıdır. Tedavi ile remisyonda seyreden ANCA ilişkili vaskülitlerin takibinde nüks önemli bir problemdir. Nüks eden olgularda rituksimab tercih edilebilir.

\section{Kaynaklar}

1. Jennette JC, Falk R, Bacon P, et al. 2012 revised international chapel hill consensus conference nomenclature of vasculitides. Arthritis Rheum 2013; 65: 1-11

2. Bosch X, Guilabert A, Font J. Antineutrophil cytoplasmic antibodies The Lancet 2006; 368: 404-18

3. Girard T, Mahr A, Noel LH, et al. Are antineutrophil cytoplasmic antibodies a marker predictive of relapse in Wegener's granulomatosis? A prospective study. Rheumatology 2001; 40: 147-51

4. Stegeman CA. Anti-neutrophil cytoplasmic antibody (ANCA) levels directed agains proteinase-3 and myeloperoxidase are helpful in predicting disease relapse in ANCA-associated small-vessel vasculitis. Nephrology Dialysis Transplantation 2002; 17: 2077-80
5. Jayne D. Treatment of ANCA-associated systemic small-vessel vasculitis. Apmis 2009; 117: 3-9

6. Puéchal X, Pagnoux C, Perrodeau É, et al. Long-term outcomes among participants in the WEGENT trial of remission-maintenance therapy for granulomatosis with polyangiitis (Wegener's) or microscopic polyangiitis. Arthritis Rheumatology 2016; 68: 690-701

7. Yilmaz N, Emmungil H, Gucenmez S ve ark. Incidence of cyclophosphamide-induced urotoxicity and protective effect of mesna in rheumatic diseases. The Journal of rheumatology 2015; 42: 1661-6

8. Carruthers D, Sherlock J. Evidence-based management of ANCA vasculitis. Best Practice Research Clinical Rheumatology 2009; 23: 367-78

9. Jayne D. Progress of treatment in ANCA-associated vasculitis. Nephrology 2009; 14: $42-8$

10. Stone JH, Merkel PA, Spiera R, et al. Rituximab versus cyclophosphamide for ANCA-associated vasculitis. New England Journal of Medicine 2010; 363: 221-32

11. Puéchal X. Targeted immunotherapy strategies in ANCA-associated vasculitis. Joint Bone Spine 2018

12. Smith RM, Merkel PA, Jayne DR. An international, open-label, randomised controlled trial comparing rituximab with azathioprine as maintenance therapy in relapsing ANCA-associated vasculitis (RITAZAREM) Rheumatology 2017

13. Tomasson G, Lavalley M, Tanriverdi K, et al. Wegener's Granulomatosis Etanercept Trial (WGET) Research Group: Relationship between markers of platelet activation and inflammation with disease activity in Wegener's granulomatosis. J Rheumatol 2011; 38: 1048

14. Keser G. Antinötrofil sitoplazmik antikor (ANCA) pozitif vaskülitler. RAED Dergisi 2009; $1: 1-14$ 